\title{
Placental Amino Acid Uptake. II. Tissue Preincubation, Fluid Distribution, and Mechanisms of Regulation
}

\author{
CARL H. SMITH ${ }^{(28)}$ AND ROSALYN DEPPER
}

Departments of Pediatrics and Pathology, Washington University School of Medicine, St. Louis Children's Hospital, St. Louis, Missouri, USA

\section{Extract}

Human placental villous tissue was incubated with the nonmetabolizable amino acid analog, $\alpha$-aminoisobutyric acid (AIB). A previous investigation demonstrated that AIB uptake into intracellular fluid is markedly increased by preincubation of tissue in a balanced salt, glucose-containing medium. This increase in transport capacity with preincubation has now been found to be blocked completely by cycloheximide, dinitrophenol, or cyanide, which indicates that the process requires protein synthesis and aerobic metabolism.

Inasmuch as increases in AIB uptake with preincubation were reported in other tissues to be regulated by amino acids in the medium, effects of amino acids were studied in the placenta. Preincubation of placental tissue with alanine did result in a transport activity which was lower than that of control preincubated tissue. However, two types of experiments indicated that this difference results from inhibition of transport activity by intracellular alanine accumulated during preincubation rather than from blockage of formation of new transport capacity during preincubation. (1) Much of the difference between control and alanine-preincubated tissue was eliminated by short additional preincubations in cycloheximide-containing, alanine-free medium; a treatment which should lower intracellular alanine concentration but not permit protein synthesis. (2) Preincubation with AIB permitted measurement of both intracellular concentration and transport activity. Addition of AIB to control preincubated tissue caused concentrating ability to fall as intracellular concentration increased. When AIB and control preincubated tissue were tested with the same intracellular AIB concentration, their transport activities were the same.

The rate of increase in concentrating ability with preincubation was inversely related to the amount of tissue per volume of preincubation medium and was enhanced by changing the medium at intervals. Preincubation of new placental tissue in medium which had been used previously for preincubation resulted in a smaller increase in concentrating ability than did preincubation of the same tissue in fresh medium. These findings were not dependent on glucose concentration or $\mathrm{pH}$. During preincubation, some as yet unidentified tissue substance is apparently released into the medium and inhibits the increase in transport activity.

\section{Speculation}

Amino acids required by the fetus must be supplied by the placenta. In vitro incubation of placental tissue has identified and partially characterized two potential mechanisms for regulation of placental amino acid uptake. The first mecha- nism increases transport activity when tissue is preincubated in vitro before measurement of uptake. The second mechanism apparently decreases existing uptake activity when amino acids are present intracellularly in high concentrations. In vivo these mechanisms could be the basis for regulation of amino acid transfer from mother to fetus.

The mammalian fetus utilizes amino acids both for the formation of new tissue protein and for catabolism $(12,13)$. Amino acids are actively transported by the placenta and their concentrations are higher in fetal blood than in maternal $(4,5$, $7,11,24)$. The relatively large quantities of amino acids required for the needs of the fetus and their importance in fetal nutrition lead to the use of in vitro techniques for the study of placental transport mechanisms $(6,16,17,23)$.

An earlier study demonstrated a technique for preparing uniform samples of villous tissue from human placentas, incubating these in vitro, and studying uptake of radioactive amino acid into intracellular water (22). Placental villous tissue was preincubated $30-300 \mathrm{~min}$ in a balanced salt, glucosecontaining medium before exposure to amino acid. This treatment caused a fivefold increase in subsequent uptake of the nonmetabolizable amino acid analog, $\alpha$-aminoisobutyric acid (AIB). The increase was shown to result from a large increase in the maximum velocity and a smail decrease in the $\mathrm{K}_{\mathrm{m}}$ of the transport process. In this paper, this phenomenon is termed "the preincubation increase in transport capacity" or sometimes simply "the preincubation increase."

This preincubation increase allows placental tissue to vary its uptake of amino acids in response to as yet unidentified environmental stimuli. Because this variation observed in vitro could be a basis for in vivo control of transfer of amino acids from mother to fetus, it was important to investigate its regulation. To achieve the precision required for such study it was first necessary to understand and control the apparent variation in inulin space with incubation of placental tissue (22). This paper describes initially studies which showed the basis of this variation and made possible more precise comparison of cellular amino acid uptake. The role of protein synthesis, aerobic metabolism, medium and tissue amino acid levels, and other metabolic factors in regulation of AIB uptake were then investigated.

\section{METHODS}

\section{GENERAL PROCEDURES}

Placentas were obtained from elective cesarean section or vaginal delivery at term. Tissue fragments were prepared, incubated, subjected to pressure-blotting, weighed, and ana- 
lyzed as described previously (22). Preincubation was performed in $125-\mathrm{ml}$ or $250-\mathrm{ml}$ Erlenmeyer flasks, $30-35 \%$ filled with medium (22), and maintained at $37^{\circ}$ in a rotating shaker bath. Except where stated, tissue concentration was $2-4$ $\mathrm{g} / 100 \mathrm{ml}$ and was uniform in any one experiment. Tissue fragments weighing $100-250 \mathrm{mg}$ were transferred to $50-\mathrm{ml}$ flasks containing $15 \mathrm{ml}$ fresh medium for incubation with 0.1 $\mathrm{mM}\left({ }^{14} \mathrm{C}\right) \mathrm{AIB}$ for 20 or $30 \mathrm{~min}$ to measure transport activity (method 2, Reference 22). Transfer to fresh medium avoided potential interference in the transport measurement itself by substances which might be present in preincubation medium. Transport activity was expressed as the ratio of the concentration of $\left({ }^{14} \mathrm{C}\right) \mathrm{AIB}$ in intracellular water to that in medium.

\section{TISSUE FLUID DISTRIBUTION}

Two methods were used for measurement of extracellular space with inulin. In method 1 , used in the studies of metabolic inhibitors and in some of the studies of amino acid preincubation, inulin was present throughout the entire preincubation-incubation sequence. In method 2, used in the remaining studies of amino acid preincubation and in studies of medium transfer (Figs. 8-10), inulin was added to all tissue in an individual experiment at a constant time ( 30 or $60 \mathrm{~min}$ ) before termination of incubation.

This second method is a change from that of the previous study. Its use was based on two preliminary experiments. Inulin space of placental villous tissue was observed previously to increase as incubation progressed. Two possibilities seemed apparent to account for the increase: (1) either inulin penetration might occur slowly and the increase might result from gradual penetration into constant fluid spaces or (2) tissue swelling might occur and the increasing inulin space might reflect an increasing tissue extracellular space.

To study the effect of inulin penetration time, flasks of placental tissue fragments were incubated for $5 \mathrm{hr}$ in Earle's medium and $\left({ }^{3} \mathrm{H}\right)$ inulin was added to each flask at various times before the termination of incubation. As shown in Figure 1, inulin space increased with penetration time. The increase was initially rapid and then considerably slower. By $30 \mathrm{~min}$, inulin space had risen to $85 \%$ of its value at $5 \mathrm{hr}$. Inasmuch as all of the tissue actually incubated for $5 \mathrm{hr}$, the increase must be caused by penetration rather than tissue swelling with incubation.

To measure tissue swelling with incubation directly, flasks of tissue fragments were incubated for periods of $1-5 \mathrm{hr}$.

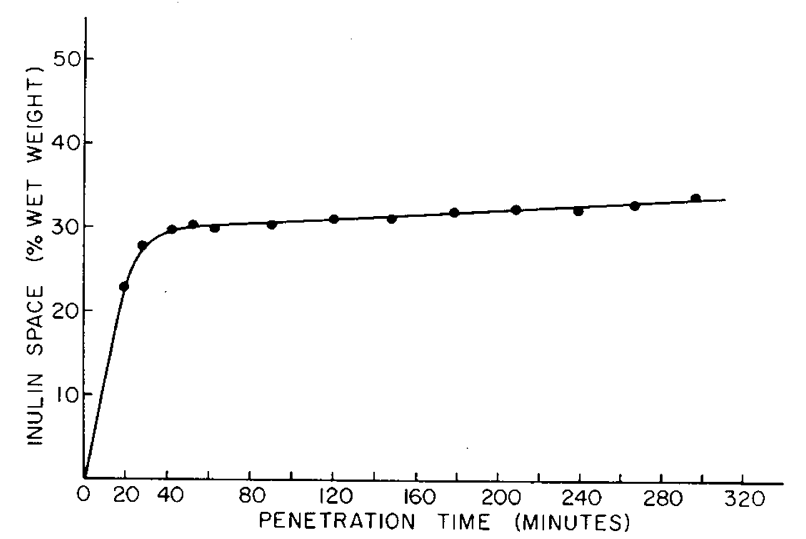

Fig. 1. Inulin space as a function of inulin penetration time. Flasks of placental tissue fragments were incubated for $5 \mathrm{hr}$. The $\left({ }^{3} \mathrm{H}\right)$ Inulin was added to individual flasks at various times before the termination of incubation. Tissue was subjected to pressure-blotting and analyzed. Inulin space as percentage of wet weight is plotted against time between inulin addition and termination of incubation. Curve shows data from one of two similar incubations of tissue from individual placentas. Inulin space increases first rapidly and subsequently more slowly with penetration time.
Inulin was added to each flask $60 \mathrm{~min}$ before the end of incubation and the inulin space attained in $1 \mathrm{hr}$ of penetration was taken as a measure of the extracellular fluid. As shown in Figure 2, extracellular fluid measured by this technique did not vary with incubation time. Appreciable tissue swelling either did not occur within $5 \mathrm{hr}$ or was compensated for by the pressure-blotting procedure.

These results demonstrate that the increase in inulin space with incubation noted previously results from increasing inulin penetration into tissue rather than actual tissue swelling. The initial phase rapid rise in Figure 1 is almost certainly caused by penetration into extracellular space. The meaning of the second phase is less clear. It could be caused by penetration into a less accessible extracellular component or, alternatively, could result from slow penetration of inulin into cellular space of the trophoblast. In support of the second possibility are the facts that syncytiotrophoblast is known to take up macromolecules by pinocytosis $(1,15)$ and that inulin has been reported to cross the human placenta in vivo from mother to fetus (3). These considerations, together with the prolonged nature of the second phase rise, indicate the difficulty in making an exact measurement of placental extracellular space with inulin (or any other marker) by allowing the penetration to reach a constant value.

For these reasons, the procedure described in method 2 was employed. Addition of inulin at a constat time before the termination of incubation allowed uniform penetration in any given study. The range of penetration times employed was chosen so that the first phase would be essentially complete and the second phase would be in its initial stage. This procedure was designed, to achieve an extracellular fluid measurement which would be as close as possible to the true value and would not be affected by variation of preincubation or incubation time in the course of the experiment.

\section{RESULTS}

\section{METABOLIC INHIBITORS AND PREINCUBATION}

Placental tissue fragments were preincubated in Earle's medium containing various concentrations of cycloheximide. At intervals, tissue was transferred to fresh medium and its ability to concentrate AIB was measured in a 20-min incubation. At each concentration of cycloheximide the AIB concentration ratio attained was plotted against preincubation time (Fig. 3). The increase in concentrating ability with preincubation seen in the control is similar to that found in the previous study. This increase was completely eliminated by cycloheximide at concentrations greater than $1-2 \mu \mathrm{g} / \mathrm{ml}$ and partially eliminated at lower concentrations.

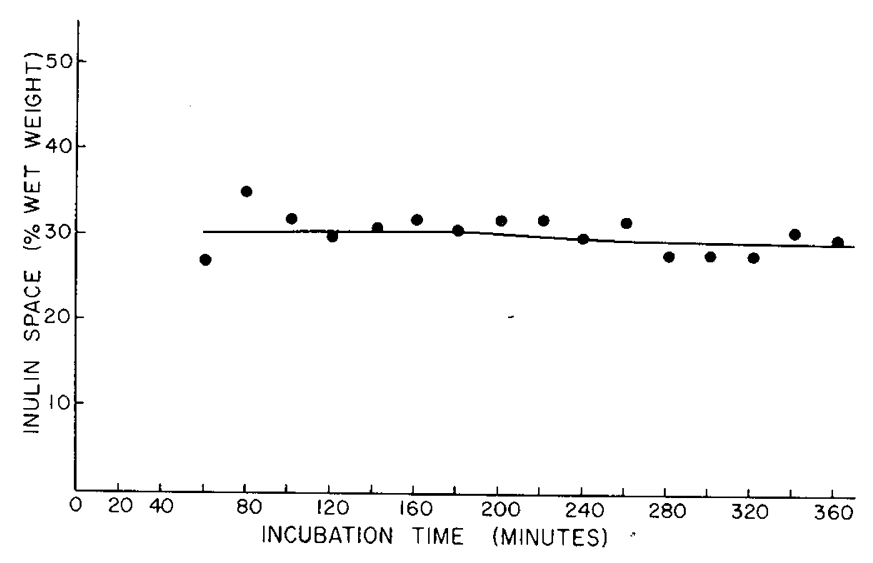

Fig. 2. Inulin space and tissue incubation time. Flasks of tissue fragments from a single placenta were incubated from $1-5 \mathrm{hr} .\left({ }^{3} \mathrm{H}\right)$ Inulin was added to each flask $1 \mathrm{hr}$ before termination of incubation. Inulin space as a percentage of wet weight is plotted against incubation time. Inulin space does not vary with incubation time. 


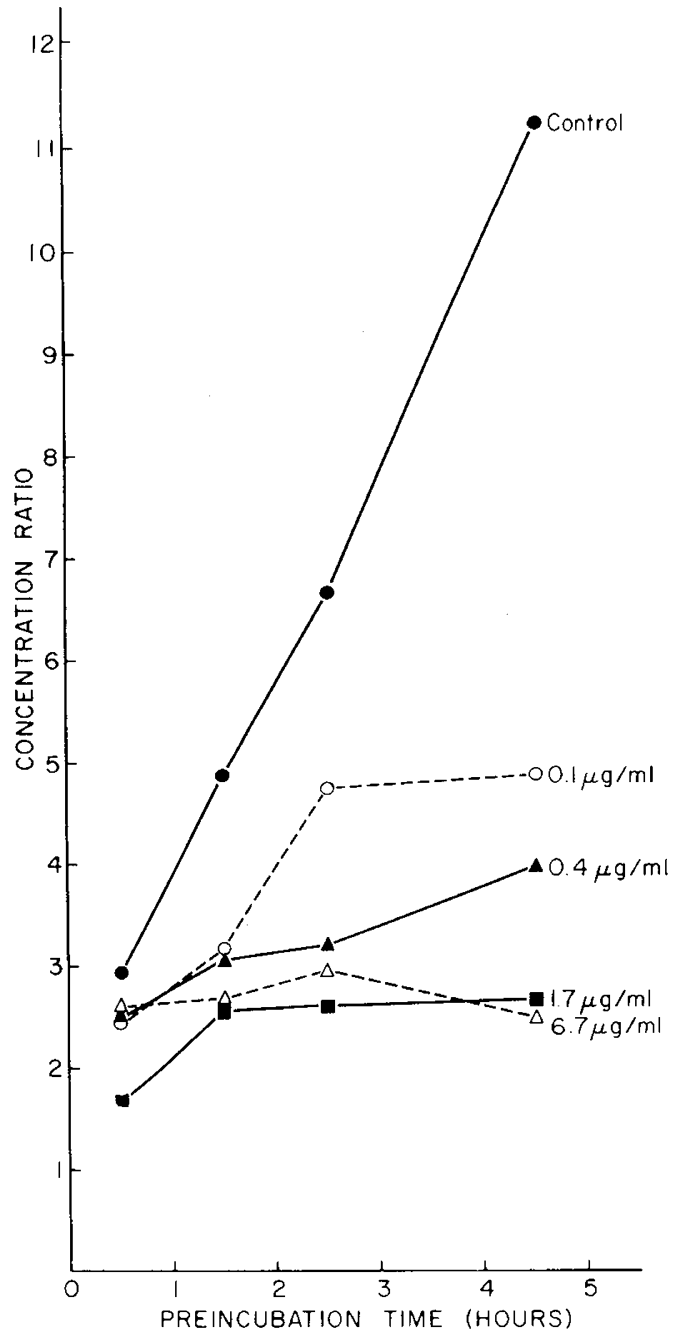

Fig. 3. Effect of cycloheximide on preincubation increase in $a$-aminoisobutyric acid (AIB) uptake. Tissue from a single placenta was preincubated in flasks containing various concentrations of cycloheximide. At four times during the preincubation period, tissue was removed from each flask, transferred to each of three incubation flasks, and incubated for $20 \mathrm{~min}$ with $0.1 \mathrm{mM}$ AIB. For each concentration of cycloheximide, the mean AIB concentration ratio attained during the 20 -min incubation is plotted against preincubation time. Lines are labeled with cycloheximide concentration. Cycloheximide in concentrations of $1.7 \mu \mathrm{g} / \mathrm{ml}$ or greater blocks the preincubation increase in transport capacity.

Because cycloheximide is a toxic substance, it was desirable to establish that the effect was reversible and not caused by nonspecific tissue toxicity. To demonstrate reversibility, a group of tissue fragments was incubated for $1.5 \mathrm{hr}$ with cycloheximide and then divided into two portions. One portion remained in cycloheximide-containing medium. The tissue of the other portion was transferred three times at 30 -min intervals to flasks of fresh medium to remove the cycloheximide. As shown in Figure 4, such transferring completely eliminated the cycloheximide effect and caused concentrating ability to increase at a rate which was actually greater than that of the control.

The effect of inhibitors of aerobic metabolism on the preincubation increase is shown in Figure 5. Both dinitrophenol and cyanide blocked the increase in concentrating ability as effectively as cycloheximide. Also shown in Figure 5 is the effect of preincubation in Earle's medium and subsequent incubation with $\left({ }^{14} \mathrm{C}\right) \mathrm{AIB}$ in the presence of cycloheximide. The increase in concentrating ability of such tissue was comparable with that of the control, which demonstrates that cycloheximide blocked the preincubation increase in transport activity rather than the transport process itself (25).

\section{AMINO ACIDS AND TISSUE UPTAKE}

To determine the effect of amino acids on the preincubation increase in transport capacity, placental tissue was preincubated in various concentrations of alanine or AIB, transferred to fresh medium, and tested in a 20-min incubation for ability to concentrate AIB. As seen in Figure 6, transport activity of tissue preincubated in $1 \mathrm{mM}$ alanine increased, but at a rate which was apparently slower than that of control tissue. The difference between control and alanine-preincubated tissue might result either from decreased formation of new transport capacity during preincubation or from decreased activity of existing transport capacity due to intracellular alanine which had accumulated during preincubation. To attempt to distinguish between these two alternatives, experiments of the type shown in Figure 7 were performed. Tissue was preincubated in $0.5,1$, or $2 \mathrm{mM}$ alanine. The increase in concentrating ability in $3 \mathrm{hr}$ was again less than that of control tissue. At $3 \mathrm{hr}$ cycloheximide was added to the preincubation flasks to block further increase by protein synthesis and at $4 \mathrm{hr}$ the tissue was transferred to fresh cycloheximide-containing, alanine-free medium to decrease alanine levels in tissue. In this medium, the level of transport activity in tissue increased sharply despite the presence of cycloheximide. This increase suggested

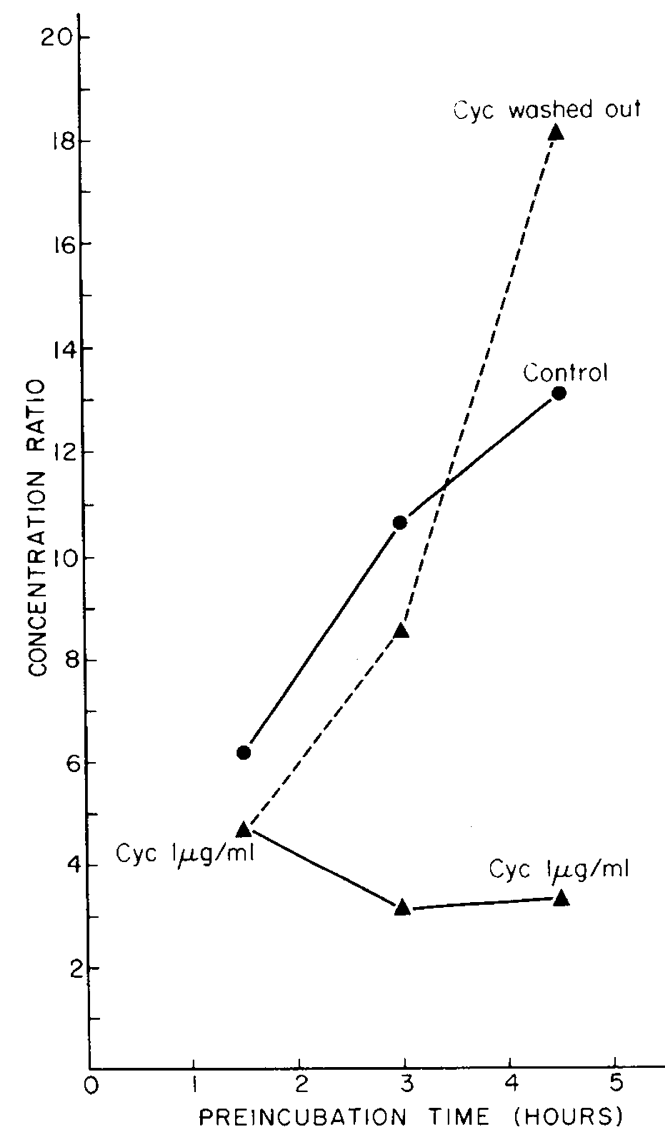

Fig. 4. Removal of cycloheximide $(C y c)$ during preincubation. Tissue from a single placenta was preincubated in medium containing cycloheximide $(1 \mu \mathrm{g} / \mathrm{ml})$ and in control medium. At $1.5 \mathrm{hr}$ a portion of tissue from the cycloheximide-containing flask was transferred three times to fresh medium to remove the inhibitor. At various intervals of preincubation, tissue was tested for ability to concentrate $\alpha$-aminoisobutyric acid and data were plotted as in Figure 3. Removal of cycloheximide reverses the blockage of the preincubation effect. 


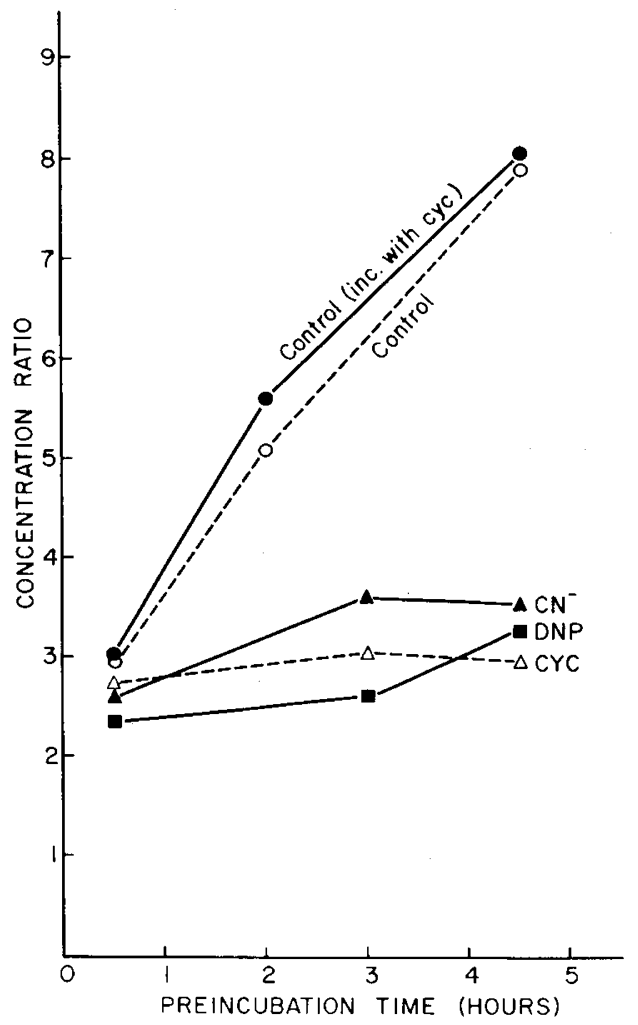

Fig. 5. Effect of dinitrophenol (DNP) and cyanide $\left(\mathrm{CN}^{-}\right)$on preincubation increase in transport. Tissue from a single placenta was preincubated in medium containing cycloheximide $(\mathrm{C} y c)$, DNP, or $\mathrm{NaCN}$ and in control medium. Tissue was tested for ability to concentrate $\alpha$-aminoisobutyric acid and data plotted as in Figure 3. DNP and $\mathrm{CN}^{-}$block the preincubation increase as effectively as cycloheximide. Portions of tissue from the control preincubation flask were also incubated with $\alpha$-aminoisobutyric acid in the presence of cycloheximide. This inhibitor has no effect on the transport process itself.

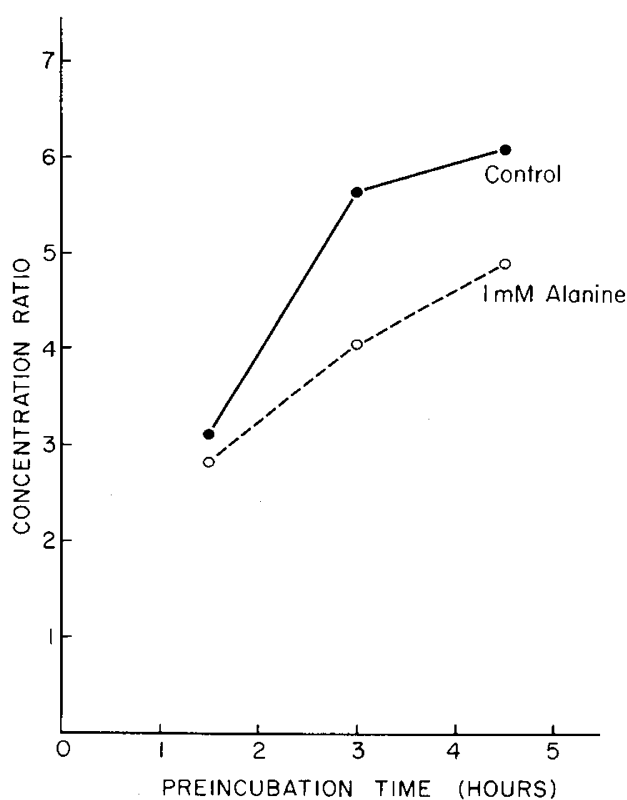

Fig. 6. Effect of alanine on preincubation increase in transport. Tissue from a single placenta was preincubated in medium containing 1 $\mathrm{mM}$ alanine and in control medium. Tissue was tested for ability to concentrate $\alpha$-aminoisobutyric acid and data were plotted as in Figure 3. a-Aminoisobutyric acid uptake of alanine-preincubated tissue increases at a rate somewhat slower than that of control tissue.

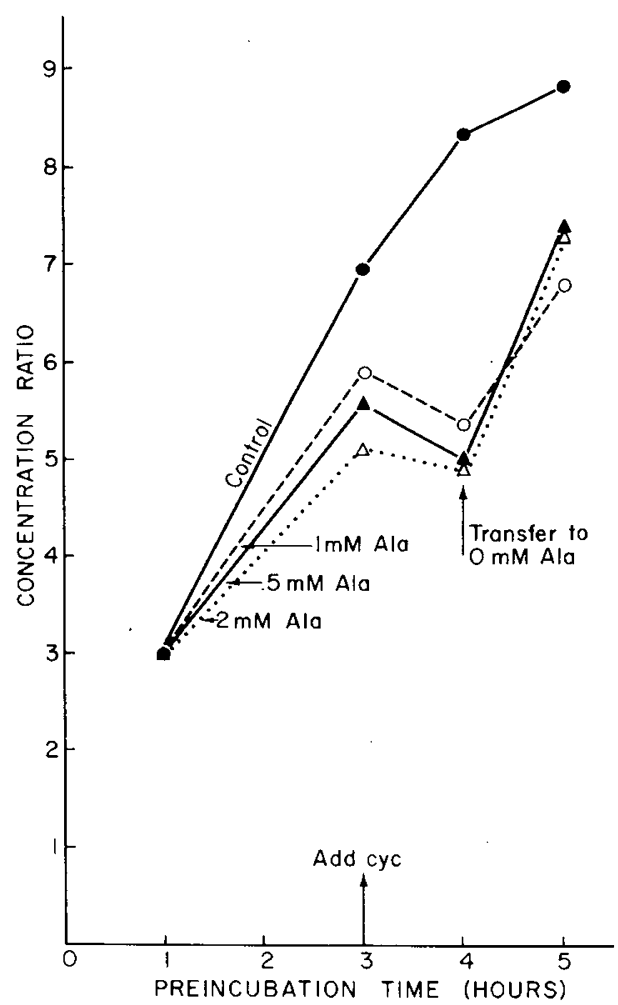

Fig. 7. Effect of removal of alanine on placental transport activity. Placental tissue was preincubated in medium containing $0.5 \mathrm{mM}, 1 \mathrm{mM}$ or $2 \mathrm{mM}$ alanine (Ala) and in control medium. At $3 \mathrm{hr}$, cycloheximide was added to all flasks to give a final concentration of $1 \mu \mathrm{g} / \mathrm{ml}$. At $4 \mathrm{hr}$, the remaining tissue in each flask was transferred to a new flask of control medium. Tissue was tested for ability to concentrate $\alpha$-aminoisobutyric acid and data were plotted as in Figure 3. Preincubation flask for the 1-hr point contained cycloheximide from zero time. Lines are labeled with alanine concentration. Data shown is from one of three similar incubations of tissue from individual placentas. At 3 and $4 \mathrm{hr}$, concentrating ability of alanine-preincubated tissue is lower than control value. However, when placed in alanine-free medium, the alanine-preincubated tissue increases sharply in concentrating ability despite the presence of cycloheximide.

that much of the difference seen at $3 \mathrm{hr}$ was caused by levels of alanine in tissue.

It was necessary to separate more clearly the potential of amino acids to suppress formation of new transport capacity from their potential to modulate the activity of existing transport capacity. For this purpose, AIB rather than alanine was used to eliminate effects caused by metabolism, and preincubation with AIB was performed in two parallel flasks with equal concentrations of AIB. One flask contained a small amount of $\left({ }^{14} \mathrm{C}\right) \mathrm{AIB}$. Tissue from this flask was analyzed directly to determine the intracellular concentrations of AIB. Tissue from the other flask, containing only $\left({ }^{12} \mathrm{C}\right) \mathrm{AIB}$, was transferred to fresh medium and incubated with $0.1 \mathrm{mM}$ $\left({ }^{14} \mathrm{C}\right) \mathrm{AIB}$ to determine tissue concentrating ability at the determined intracellular AIB concentration.

Figure 8 shows the results of a study using this technique. After $3.5 \mathrm{hr}$ of preincubation of tissue in $1.5 \mathrm{mM} \mathrm{AIB}$, the intracellular $\mathrm{AIB}$ concentration was $9 \mathrm{mM}$ and concentrating ability was considerably less than that of control tissue preincubated in the absence of AIB. Addition of AIB to the medium of portions of the control tissue caused the intracellular concentration to rise and tissue concentrating activity to fall. After $1 \mathrm{hr}$ both had attained levels comparable to those of tissue originally preincubated in AIB. This experiment was repeated three times with similar results and was unaffected by brief rinsing of tissue to remove the small quantity of trapped extracellular AIB before measurements of 


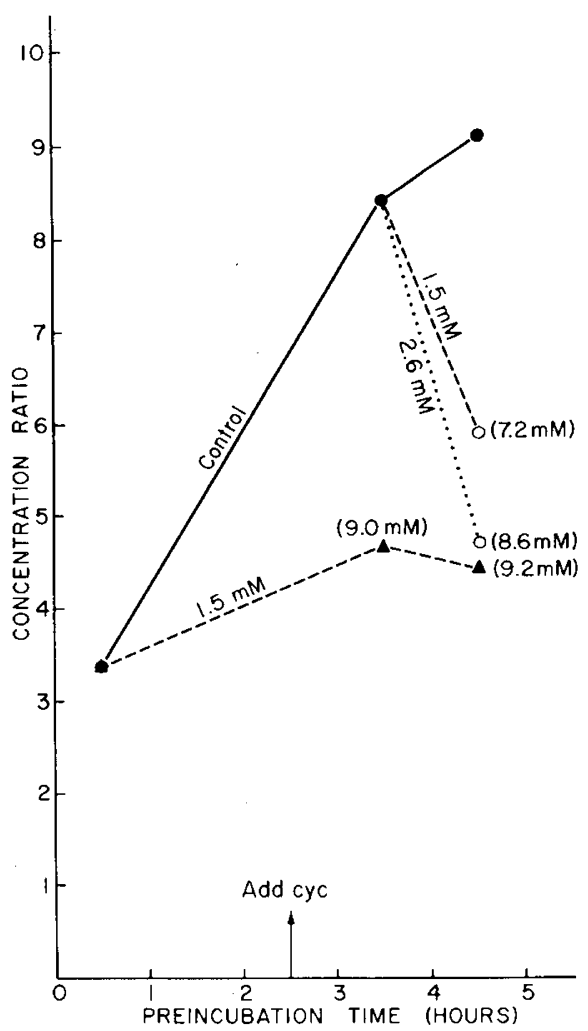

Fig. 8. Effect of intracellular $\alpha$-aminoisobutyric acid (AIB) concentration on tissue AIB uptake. Placental tissue was preincubated in medium containing $1.5 \mathrm{mM}$ AIB and in control medium. At $2.5 \mathrm{hr}$, cycloheximide was added to all flasks to give a final concentration of 2 $\mu \mathrm{g} / \mathrm{ml}$. At $3.5 \mathrm{hr}$, AIB was added to the medium of portions of control tissue to give concentrations of 1.5 and $2.6 \mathrm{mM}$. At the times shown, tissue was removed from each preincubation flask, transferred to each of three incubation flasks, and incubated for $30 \mathrm{~min}$ with $0.1 \mathrm{mM}$ AIB. Mean concentration ratios attained in such incubations are plotted against preincubation time. The preincubation flask for the 1-hr point contained cycloheximide from zero time. Parallel preincubations with $\left({ }^{14} \mathrm{C}\right)$ AIB were used to determine intracellular AIB concentrations. Lines are labeled with AIB concentration in preincubation medium. The intracellular AIB concentration is given in parentheses next to data points. Addition of AIB to control preincubated tissue causes concentrating ability to decrease. When control and original AIB-preincubated tissue are studied with the same intracellular concentrations, their 30-min AIB uptake is the same.

uptake and concentration. It is clear that intracellular AIB or alanine can decrease ability to concentrate external AIB. Furthermore, the concentrating ability of AIB-preincubated tissue is the same as that of control tissue provided that both are tested with the same intracellular AIB concentration.

\section{MEDIUM CHANGE DURING PREINCUBATION}

In the study with cycloheximide, it was noted that changing the preincubation medium frequently not only eliminated the effect of the cycloheximide, but also enhanced the effect of preincubation. The resulting increase in transport activity was greater than that attained during the control preincubation (Fig. 4). To explore this finding, placental tissue was subjected to preincubation in the absence of cycloheximide. Frequent changing of the medium was again found to enhance the preincubation effect and concentration ratios $50 \%$ greater than those of control preincubated tissue were attained.

The relation of the quantity of tissue per volume of medium to the increase in transport with preincubation was determined. Figure 9 demonstrates that preincubation at a concentration of $1.5 \mathrm{~g}$ tissue $/ 100 \mathrm{ml}$ medium resulted in a greater increase in transport than did preincubation at 6.0 $\mathrm{g} / 100 \mathrm{ml}$. Changing the medium during preincubation at the dilute concentration further enhanced the effect. Glucose concentrations in medium after the $4.5 \mathrm{hr}$ of preincubation at $6.0 \mathrm{~g} / 100 \mathrm{ml}$ were $155-165 \mathrm{mg} / 100 \mathrm{ml}$. In the presence of cycloheximide, differences in preincubation effects due to concentration of tissue and changing of the medium did not occur (Fig. 9, lower lines).

These findings suggested that the preincubation effect might be inhibited by a substance released from the tissue into the medium. To investigate this possibility more directly, placental tissue was incubated at $4.0 \mathrm{~g} / 100 \mathrm{ml}$ for $6 \mathrm{hr}$. The medium was separated from the tissue and glucose added to restore the concentration to $200 \mathrm{mg} / 100 \mathrm{ml}$. When equilibrated with $5 \%$ $\mathrm{CO}_{2}$ in oxygen, the $\mathrm{pH}$ of this "old preincubation medium" was 7.35 , the same as that of fresh medium. The effectiveness of old preincubation medium in supporting the increase in AIB uptake was determined. The results (Fig. 10) demonstrate that at both concentrations of tissue tested, the increase in transport activity on preincubation in old medium is considerably less than that on preincubation in fresh medium.

\section{DISCUSSION}

Based on this work and the previous investigation (22), two apparently distinct mechanisms for control of placental amino acid uptake can be described. The first mechanism is responsible for the increase in tissue capacity for AIB uptake with preincubation; the second permits regulation of existing

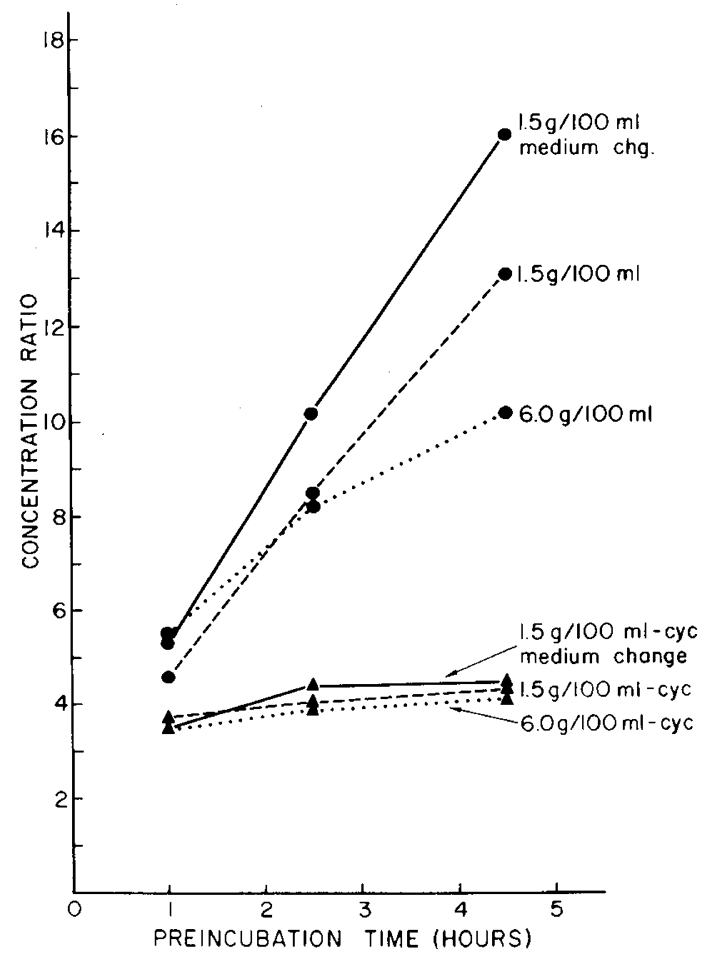

Fig. 9. Effect of concentration of tissue and change of medium on preincubation increase in transport. Placental tissue was preincubated in cycloheximide-containing $(c y c)$ and control medium and tested for concentrating ability. Data plotted as in Figure 8. Lines are labeled with quantity of tissue per milliliter of preincubation medium. Concentration of tissue in incubation medium remained constant. Lines marked medium chg. indicate medium was changed twice between 1 and $2.5 \mathrm{hr}$. Data shown is from one of three similar incubations of tissue from individual placentas. In the absence of cycloheximide, preincubation increase is greater at lower concentrations of tissue and is further enhanced by changing medium. In the presence of cycloheximide, these effects do not occur. 


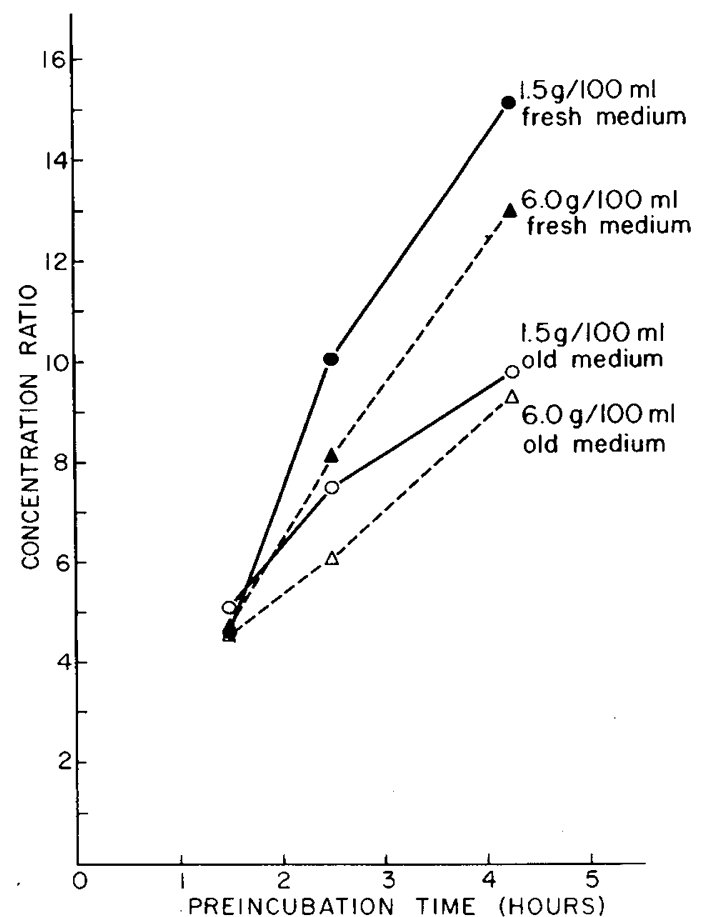

Fig. 10. Effect of previously used medium on preincubation increase in $\alpha$-aminoisobutyric aciá uptake. Tissue from a single placenta was preincubated for $6 \mathrm{hr}$ at a concentration of $6.0 \mathrm{~g}$ tissue $/ 100 \mathrm{ml}$ medium. The tissue was removed and glucose was added to restore the concentration to $200 \mathrm{mg} / 100 \mathrm{ml}$. Tissue from a second placenta was then preincubated in this previously used medium and in fresh medium. Tissue was tested for concentrating ability and data plotted as in Figure 8. Lines are labeled with type of preincubation medium and concentration of tissue during preincubation. The figure shows data from one of three similar incubations, each of which involved tissue from two placentas as described. Increase in transport capacity is less when previously used medium is employed for preincubation.

tissue activity by high concentrations of intracellular amino acid.

The first mechanism, which brings about the increase in tissue uptake with in vitro preincubation, was shown previously to result in an increase in maximum velocity of uptake. Studies with inhibitors now indicate that this process requires protein synthesis and aerobic metabolism. In these respects it is apparently similar to increases in amino acid transport described in immature chick and rat muscle tissue $(8-10)$ and rat uterus $(20)$ and found to be limited to a particular transport system. This mechanism appears to involve synthesis of a protein which is rate limiting to transport, perhaps a component of a membrane carrier system.

In chick and rat muscle, increase in transport activity by this mechanism can be blocked by the presence in the preincubation medium of high concentrations of amino acids transported by the same pathway as $\operatorname{AIB}(9,18)$. The studies described in this paper were designed to determine whether in the placenta this mechanism is regulated by these amino acids at concentrations present in the in vivo tissue environment. The concentrations used (1-2 $\mathrm{mM})$ were chosen to be comparable with the sum of the maternal plasma concentrations of amino acids shown to be transported similarly to AIB in a number of tissues $(5,9,11,14,18)$.

Three types of experiments from this study indicate that such amino acids at these apparently physiologic concentrations do not directly control the preincubation increase in transport capacity. (1) Although transport activity was lower in tissues which had been preincubated in the presence of alanine, the complete blockage of the preincubation increase seen in certain muscle tissues (9) was never observed in placental tissue. (2) Prolonged incubation in the presence of high concentrations of alanine necessarily leads to high intracellular alanine levels which could in themselves influence transport activity. To assess the significance of this possibility, the cellular alanine concentrations were permitted to decrease by an additional short incubation in the presence of cycloheximide to block protein synthesis. This treatment caused transport activity of the alanine preincubated tissue to increase to levels nearly as great as those of control tissue. (3) AIB was used to attempt to block the preincubation increase and parallel preincubations with the same concentrations of radioactive $\mathrm{AIB}$ were performed to determine intracellular concentration. These experiments demonstrated clearly that when control and AIB-preincubated placental tissue were tested with the same intracellular AIB concentrations, their transport activities were the same. Therefore, in apparent contrast to findings in immature muscle (9), this study of the placenta has not shown blockage of the increase in transport capacity by amino acids transported by the same pathway as AIB (26).

The rate of increase in concentrating ability with preincubation was inversely related to the amount of tissue per volume of medium and was enhanced by changing the medium at intervals. Furthermore, use of medium which had previously been employed for preincubation resulted in a lower increase in concentrating ability than did use of fresh medium. These phenomenon were not dependent on the supply of glucose or the $\mathrm{pH}$. During preincubation, some as yet unidentified tissue substance is apparently released into the medium and inhibits the increase in transport activity. Inasmuch as the effects of tissue concentration and medium change did not occur in the presence of cycloheximide, the tissue substance must regulate a process which is dependent on protein synthesis.

The second mechanism for regulation of AIB uptake apparently permits high intracellular concentrations to decrease existing tissue transport activity and inhibit further uptake. Evidence for existence of such a mechanism is shown in the experiment of Figure 8 in which the addition of AIB to placental tissue leads to high intracellular concentrations and to a decrease in transport activity. In other tissue systems, a variety of mechanisms has been proposed to account for similar decreases in transport activity $(2,8,10,14,19,21)$. In placental tissue, this phenomenon has not been investigated in detail and the mechanism remains to be determined.

\section{SUMMARY}

Placental villous tissue was incubated with the nonmetabolizable amino acid analog, $\alpha$-aminoisobutyric acid, to study uptake into the intracellular fluid. Two potential mechanisms for regulation of uptake have been identified. The first mechanism brings about an increase in cellular concentrating ability with preincubation of tissue in a balanced salt, glucosecontaining medium. The second mechanism causes a decrease of existing transport activity by amino acids at high intracellular concentrations.

Studies with inhibitors indicate that the first mechanism, the preincubation increase, requires protein synthesis and aerobic metabolism. In apparent contrast to results in other tissues, no blockage of the preincubation increase by alanine or AIB could be demonstrated in placenta, provided that control and amino acid-preincubated tissue were tested with the same intracellular amino acid concentration. Variation of the amount of tissue per volume of medium and studies with reuse of previously used preincubation medium indicated that the increase in transport activity is inhibited by an as yet unidentified tissue substance which is released into the medium

In vivo these two regulatory mechanisms could provide a basis for regulation of amino acid transfer from mother to fetus. 


\section{REFERENCES AND NOTES}

1. Ashley, C. A.: Study of the human placenta with the electron microscope. Arch. Pathol., 80: 377 (1965).

2. Belkhode, M. L., and Scholefield, P. G.: Interactions between amino acids during transport and exchange diffusion in Novikoff and Ehrlich acites tumor cells. Biochim. Biophys. Acta, 173: 290 (1969).

3. Brandes, J. M., Abramovici, H., and Peretz, A.: Le passage de l'inuline de la femme enceinte au foetus dans la grossesse normale et au cours d'une cesarienne. Rev. Franc. Gynecol., 67: 133 (1972).

4. Christensen, H. N., and Streicher, J. A.: Association between rapid growth and elevated cell concentrations of amino acids. I. In fetal tissues. J. Biol. Chem., 175: 95 (1948).

5. Cockburn, F., Giles, M., Robins, S. P., and Forfar, J. O.: Free amino acid composition of human amniotic fluid at term. J. Obstet. Gynaecol. Brit. Commonw., 80: 10 (1973).

6. Dancis, J., Money, W. L., Springer, D., and Levitz, M.: Transport of amino acids by placenta. Amer. J. Obstet. Gynecol., 101: 820 (1968).

7. Feldman, B. H., and Christensen, H. N.: Placenta transport of model amino acids. Proc. Soc. Exp. Biol. Med., 109: 700 (1962).

8. Franchi-Gazzola, R., Gazzola, G. C., Ronchi, P., Saibene, V., and Guidotti, G. G.: Regulation of amino acid transport in chick embryo heart cells. II. Adaptive control sites for the "A mediation."Biochim. Biophys. Acta, 291: 545 (1973)

9. Gazzola, G. C., Franchi, R., Saibene, V., Ronchi, P., and Guidotti, G. G.: Regulation of amino acid transport in chick embryo heart cells. I. Adaptive system of mediation for neutral amino acids. Biochim. Biophys. Acta, 266: 407 (1972).

10. Gazzola, G. C. Franchi-Gazzola, R., Ronchi, P., and Guidotti, G. G.: Regulation of amino acid transport in chick embryo heart cells. III. Formal identification of the A mediation as an adaptive transport system. Biochim. Biophys. Acta, 311: 292 (1973).

11. Ghadimi, H., and Pecora, P.: Free amino acids of cord plasma as compared with maternal plasma during pregnancy. Pediatrics, 33: $500(1964)$

12. Gresham, E. L., James, E. J., Raye, J. R., Battaglia, F. C. Makowski, E. L., and Meschia, G.: Production and excretion of urea by the fetal lamb. Pediatrics, 50: 372 (1972).

13. Gresham, E. L., Simons, P. S., and Battaglia, F. C.: Maternal-fetal urea concentration difference in man: Metabolic significance. $J$. Pediat., 79: 809 (1971)

14. Heinz, E.: Transport of amino acids by animal cells. In: L. E. Hokin: Metabolic Pathways, Ed. 3, Vol. 6, p. 455 (Academic Press, New York, 1972).

15. King, B. F., and Enders, A. C.: Protein absorption by the guinea pig chorioallantoic placenta. Amer. J. Anat., l30: 409 (1971).

16. Litonjua, A. D., Canlas, M., Soliman, J., and Paulino, D. Q.: Uptake of $\alpha$-aminoisobutyric acid in placental slices at term.

Copyright (c) 1974 International Pediatric Research Foundation, Inc.
Amer. J. Obstet. Gynecol., 99: 242 (1967).

17. Longo, L. D., Yuen, P., and Gusseck, D. J.: Anaerobic, glycogen-dependent transport of amino acids by the placenta. Nature, 243: 531 (1973).

18. Oxender, D. L., and Christensen, H. N.: Distinct mediating systems for the transport of neutral amino acids by the Ehrlich cell. J. Biol. Chem., 238: 3686 (1963).

19. Pall, M. L.: Amino acid transport in neurospora crassa. IV. Properties and regulation of a methionine transport system. Biochim. Biophys. Acta, 233: 201 (1971).

20. Riggs, T. R., and Pan, M. W.: Transport of amino acids in to the oestrogen-primed uterus: Enhancement of the uptake by a preliminary incubation. Biochem. J., 128: 19 (1972).

21. Ring, K., and Heinz, E.: Active amino acid transport in streptomyces hydrogenans. I. Kinetics of uptake of $\alpha$-aminoisobuytric acid. Biochem. Z., 344: 446 (1966).

22. Smith, C. H., Adcock, E. W., III, Teasdale, F., Meschia, G., and Battaglia, F. C.: Placental amino acid uptake: Tissue preparation, kinetics and preincubation effect. Amer. J. Physiol., 224: 558 (1973).

23. Sybulski, S., and Tremblay, P. C.: Uptake and incorporation into protein of radioactive glycine by human placentas in vitro. Amer. J. Obstet. Gynecol., 97: 1111 (1967).

24. Young, M.: Placental transport of amino acids. In: J. H. P. Jonx is: Nutricia Symposium: Metabolic Processes in the Foetus and Newborn Infant, p. 97 (The Williams \& Wilkins Co., Baltimore, 1971).

25. A similar study of tissue preincubated in Earle's medium and incubated with $\left({ }^{14} \mathrm{C}\right) \mathrm{AIB}$ in the presence of DNP or cyanide, demonstrated that these substance reduced concentrating ability only $50 \%$. This finding is similar to a recent report in the literature (17). Thus, the effect of dinitrophenol and cyanide shown in Figure 5 is caused (at least in part) by blockage of the preincubation increase in transport capacity.

26. An experiment similar to that shown in Figure 8 was described in chick embryo heart cells with quite different results (9). In that system, a secondary, short term incubation with alanine of control preincubated cells resulted in a large increase in control preincubated cells resulted in a large increase in intracellular concentration with only a very small decrease in
transport activity. The marked difference between this result and transport activity. The marked difference between this result and
that in the placenta emphasizes the apparent difference in regulation between the two tissue systems.

27. Financial support for this investigation was provided by Grant no. 42700 from The National Foundation-March of Dimes and by funds from General Research Support Grant no. 54898 A from the United States Public Health Service.

28. Requests for reprints should be addressed to: C. H. Smith, M.D., Department of Pediatrics, Washington University School of Medicine, 500 S. Kingshighway, St. Louis, Missouri 63110 (USA).

29. Accepted for publication February 15, 1974. 